\title{
12. Studies on Kernicterus. III
}

\section{Developmental Change in Brain Bilirubin Level in Gunn Rats*)}

\author{
By Yoshio SAWASAKI, Noriko Yamada, and Hiroshi NaKaJIMA \\ Department of Biochemical Genetics, Medical Research Institute, \\ Tokyo Medical and Dental University, Tokyo 113
}

(Comm. by Kenji YamaokA, M. J. A., Jan. 12, 1976)

Introduction. Bilirubin toxicity has been reported to be due to the primary interference with mitochondrial functions. ${ }^{1)-3)}$ However, these studies have been limited to in vitro situations. It is not clear that the bilirubin levels used reflected the actual level in the kernicteric brain since no attempt has yet been made to determine brain bilirubin content.

In the previous communications, ${ }^{4), 5)}$ it was reported that the homozygous Gunn rats show marked cerebellar hypoplasia due to hyperbilirubinemia, and cerebellar DNA synthesis was impaired in these mutant rats from 10 days of age. One possible explanation for such a development-dependency of impaired DNA synthesis might be that the bilirubin accumulated in the cerebellum from a certain stage of the development. Special interest will therefore be given to the investigation of the brain bilirubin level in developing Gunn rat.

In the present communication, bilirubin level in Gunn rat brain was determined by the method based on chloroform extraction and direct spectrophotometrical estimation of bilirubin in tissue.

Materials and methods. Male heterozygous $(\mathrm{Jj})$ and homozygous (jj) Gunn rat littermates born from Jj mother were used in this study. At least 6 animals were sacrificed in each experiment.

Determination of tissue bilirubin. Animals were anesthetized with ether and perfused through the left ventricle of the heart with $0.25 \mathrm{M}$ sucrose solution. The brain and liver were removed and homogenized by Potter-Elvehjem homogenizer with Teflon pestle with 3 volumes of $0.25 \mathrm{M}$ sucrose solution. The extraction mixture containing $1 \mathrm{ml}$ tissue homogenate, $4 \mathrm{ml}$ distilled water, $5 \mathrm{ml}$ chloroform, and $12 \mathrm{ml}$ methanol was homogenized. After adding $8 \mathrm{ml}$ of distilled water, the whole mixture was transfered to a plastic tube, and centrifuged for $30 \mathrm{~min}$ at $10,000 \times \mathrm{g}$. The two clear phases and the thin disc-shaped interphase were then separated. Unconjugated bilirubin was identified in the lower chloroform phase. These procedures were

*) This investigation was supported in part by the Grants No. 92032, 96036 and 944030 from the Ministry of Education of Japan. 

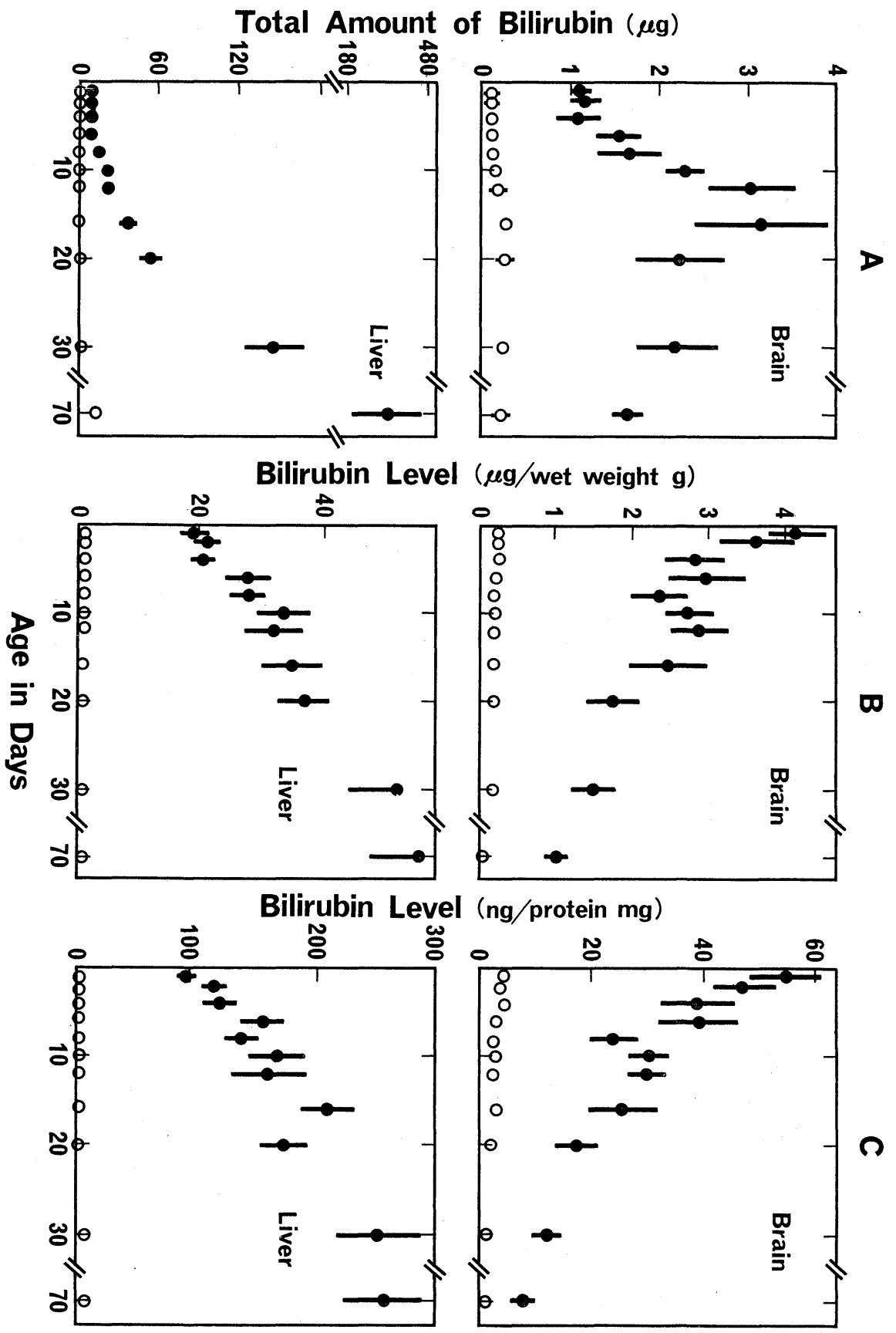

Fig. 1. Postnatal change in bilirubin content (a) and level (b, c) of Gunn rat brain and liver. Bilirubin level is expressed as bilirubin per $\mathrm{g}$ wet weight (b) or $\mathrm{mg}$ protein (c). At 1 day and 2 days of age, two animals were combined for determining tissue bilirubin. Each point represents mean \pm S.D. of 6 samples. $\bigcirc$ : heterozygotes; $\bullet$ : homozygotes. 
Table I. Regional distribution of bilirubin in Gunn rat brain

\begin{tabular}{lccr}
\hline & \multicolumn{3}{c}{ Days after birth } \\
\cline { 2 - 4 } & 8 & 16 & \multicolumn{1}{c}{30} \\
\hline & & ng/protein $\mathrm{mg}$ \\
Cerebellum & $28.8 \pm 1.4$ & $24.8 \pm 1.2$ & $10.6 \pm 0.2$ \\
Cerebral Cortex & $27.6 \pm 1.5$ & $23.4 \pm 1.1$ & $9.8 \pm 0.9$ \\
Colliculi & $27.2 \pm 2.0$ & $23.7 \pm 1.5$ & $10.8 \pm 1.0$ \\
Caudate Nucleus & $28.0 \pm 1.4$ & $22.3 \pm 0.6$ & $9.9 \pm 0.8$ \\
Thalamus & $26.8 \pm 0.1$ & $23.4 \pm 0.8$ & $9.6 \pm 0.8$ \\
Hypothalamus & $27.5 \pm 1.7$ & $23.0 \pm 1.5$ & $9.2 \pm 0.6$ \\
Hippocampus & $27.4 \pm 1.4$ & $22.8 \pm 1.3$ & $9.2 \pm 0.6$ \\
Brain Stem & $26.5 \pm 1.2$ & $24.2 \pm 1.1$ & $9.9 \pm 0.3$ \\
\hline
\end{tabular}

Each value represents mean \pm S.D. of 4 experiments.

carried out in dim light at below $4^{\circ}$. Bilirubin in the chloroform phase was determined from absorption difference at $452 \mathrm{~nm}$ and $490 \mathrm{~nm}$ on a Hitachi two wavelength double beam spectrophotometer, model 356 , using commercial bilirubin as a standard. The recovery of bilirubin in this procedure was approximately $65 \%$. Protein was determined by Biuret reaction with bovine serum albumin as a standard. The regional distribution of bilirubin in Gunn rat brain was determined by a modified procedure using micro-cell. For a determination, six samples were combined.

Results and discussion. Fig. 1a) shows the postnatal change in bilirubin content in Gunn rat brain and liver determined by the method described under "Materials and methods." The procedure for bilirubin extraction from tissue was based partly on the method of Bratlid \& Winsnes $\left.{ }^{6}\right)$ which was designed for serum bilirubin determination. The liver was taken for a comparative purpose since it also shows highly active DNA synthesis after birth like cerebellum but exhibits neither pathological change ${ }^{7), 8)}$ nor impaired DNA synthesis ${ }^{5)}$ in jj Gunn rat. The bilirubin found in jj brain was extremely low, increased gradually after birth until 16 days of age and then decreased. Variation was from 1 to $3 \mu \mathrm{g}$. In contrast, the bilirubin content in $\mathrm{jj}$ liver increased exponentially after birth. The low amount of bilirubin in $\mathrm{jj}$ brain may suggest that too much bilirubin has been used in in vitro studies in which the primary toxicity of bilirubin to mitochondria has been reported. ${ }^{1)-3)}$ Diamond and Schmid ${ }^{9)}$ have described that $10.6 \mu \mathrm{g}$ of bilirubin was transfered per gram of brain in the neurotoxic newborn guinea pig perfused with ${ }^{14} \mathrm{C}$-bilirubin, and showed that such a bilirubin content could not uncouple oxidative phosphorylation of brain mitochondria. Also, Menken and Weinbach ${ }^{10)}$ have reported the failure to demonstrate impaired oxidative phosphorylation in mitochondria from jj Gunn rat brain. In addition, Schutta et al. ${ }^{11)}$ cast serious doubt 
from histological observation of $j \mathrm{j}$ rat cerebellum upon whether primary bilirubin toxicity was to the mitochondrial functions. In conclusion, it seems premature to discuss primary bilirubin cytotoxicity.

A clear difference was observed in developmental change of bilirubin level between brain and liver (Fig. 1b). Brain bilirubin level decreased after birth in contrast with that in liver which increased steadily and reached a constant level. These findings appear to imply blood brain barrier phenomenon to bilirubin. ${ }^{12)-14)}$ The tissue bilirubin level expressed in bilirubin per protein content may also be useful in the study of the relationship between an enzyme and bilirubin level in brain. ${ }^{15), 16)}$ In this expression, the brain bilirubin level in $j \mathrm{j}$ rat showed more rapid decrease after birth (Fig. 1c). In addition, as shown in Table I, no selectivity was found in the regional distribution of bilirubin in $\mathrm{jj}$ rat brain throughout development.

These observations seem to indicate that the development-dependency of impaired DNA synthesis in jj cerebellum might be due to the unique nature of rat cerebellar development, postnatal neurogenesis, ${ }^{17}$ ) and not to the change in the brain bilirubin level.

\section{References}

1) Day, R. L.: Proc. Soc. Exper. Biol. \& Med., 85, 261 (1954).

2) Cowger, W., Igo, R. P., and Labbe, R. F.: Biochemistry, 4, 2763 (1965).

3) Noir, B. A., Boveris, A., Garaza Pereira, A. M., and Stoppani, A. O. M.: FEBS Letters, 27, 270 (1972).

4) Sawasaki, Y., Yamada, N., and Nakajima, H.: Proc. Japan Acad., 49, 840 (1973).

5) Yamada, N., Sawasaki, Y., and Nakajima, H.: Proc. Japan Acad., 49, 846 (1973).

6) Bratlid, D., and Winsnes, A.: Scand. J. Clin. Lab. Invest., 28, 41 (1971).

7) Schmid, R., Axelrod, J., Hammaker, L., and Swarm, R. L.: J. Clin. Invest., 37, 1123 (1958).

8) Picarki, R., Gardiol, D., Gautier, A., and Magnenat, P.: Rev. Int. Hépat., 17, 875 (1967).

9) Diamond, I., and Schmid, R.: Science, 155, 1288 (1967).

10) Menken, M., and Weinbach, E.: J. Neurochem., 14, 189 (1967).

11) Schutta, H. S., Johnson, L., and Neville, H. E.: J. Neurophath. Exper. Neurol., 29, 296 (1970).

12) Menken, M., Barrett, P. V. D., Swarm, R. L., and Berlin, N. I.: Arch Neurol., 15, 68 (1966).

13) Brodersen, R.: Scand. J. Clin. Lab. Invest., 30, 95 (1972).

14) Lüders, D.: Z. Kinderheilk, 116, 57 (1973).

15) Yamada, N., Sawasaki, Y., and Nakajima, H.: in Fourth International Meeting of the International Society for Neurochemistry (Tokyo), Abstract pp. 344 (1973).

16) Yamada, N., Sawasaki, Y., and Nakajima, H.: Proc. Japan Acad., 52 (1976) in press.

17) Altman, J., and Das, G. D.: J. Comp. Neurol., 126, 337 (1966). 